\title{
RECONCILING TRENDS IN U.S. MALE EARNINGS VOLATILITY: RESULTS FROM A FOUR DATA SET PROJECT
}

\author{
Robert A. Moffitt \\ Working Paper 27664 \\ http://www.nber.org/papers/w27664 \\ NATIONAL BUREAU OF ECONOMIC RESEARCH \\ 1050 Massachusetts Avenue \\ Cambridge, MA 02138 \\ August 2020
}

The author would like to Joe Altonji and the participants of the Summer 2020 NBER Conference in Research and Wealth workshop for comments, as well as the other team members on this project: John Abowd, Christopher Bollinger, Michael Carr, Charles Hokayem, Kevin Mckinney, Emily Wiemers, Sisi Zhang, and James Ziliak. The views expressed herein are those of the author and do not necessarily reflect the views of the National Bureau of Economic Research.

NBER working papers are circulated for discussion and comment purposes. They have not been peer-reviewed or been subject to the review by the NBER Board of Directors that accompanies official NBER publications.

(C) 2020 by Robert A. Moffitt. All rights reserved. Short sections of text, not to exceed two paragraphs, may be quoted without explicit permission provided that full credit, including () notice, is given to the source. 
Reconciling Trends in U.S. Male Earnings Volatility: Results from a Four Data Set Project Robert A. Moffitt NBER Working Paper No. 27664

August 2020

JEL No. C33,J3

\begin{abstract}
$\underline{\text { ABSTRACT }}$
There is a large literature on earnings and income volatility in labor economics, household finance, and macroeconomics. One strand of that literature has studied whether individual earnings volatility has risen or fallen in the U.S. over the last several decades. There are strong disagreements in the empirical literature on this important question, with some studies showing upward trends, some downward trends, and some flat trends. Some studies have suggested that the differences are the result of using flawed survey data instead of more accurate administrative data. This paper provides an overview of a project attempting to reconcile these findings with four different data sets and six different data series--three survey and three administrative data series, including two which match survey respondent data to their administrative data. Using common specifications, measures of volatility, and other treatments of the data, the papers show almost uniformly a lack of any significant long-term trend in male earnings volatility over the last 30 years. Moreover, the survey and the administrative data almost entirely agree on that longterm stability when the comparison is done properly. Several possible explanations for the differing finds in past work are suggested by the papers. The stability of earnings volatility raises many questions for future research on trends in the U.S. labor market.
\end{abstract}

\author{
Robert A. Moffitt \\ Department of Economics \\ Johns Hopkins University \\ 3400 North Charles Street \\ Baltimore, MD 21218 \\ and IZA \\ and also NBER \\ moffitt@jhu.edu
}


The literature on labor market volatility is vast and touches on multiple areas of macroeconomics, household finance, labor economics, and overlaps between them. The classic study of permanent vs transitory components of income and their implications for consumption, saving, and the marginal propensity to consume is just one example (Friedman, 1957; Hall and Mishkin, 1982). On the micro level, this literature has spilled over into household finance, with its concern with liquidity constraints, ability to deal with income shocks, possible inadequacy of assets to deal with such shocks, and consequent inability to smooth consumption sufficiently (Carroll, 1997; Gourinchas and Parker, 2002). In labor economics, a literature going back to the 1960s and 1970s on sectoral models of the labor market, with one sector characterized by high wages and stable jobs and another characterized by low wages and unstable jobs, has reemerged in recent discussions of technological change and the decline of union and manufacturing jobs, since the latter generally are more stable than average (Taubman and Wachter, 1986; Katz and Autor, 1999). The impact of income uncertainty on investments in human capital, both educational and on-the-job, and on investments in children at young ages, has generated yet another discussion in labor economics as well (Levhari and Weiss, 1974; Carneiro and Ginja, 2016)

An important empirical branch of this literature concerns whether volatility has changed over time in the U.S. A priori, whether labor market volatility should be expected to have risen or fallen differs by perspective. On the one hand, the just-mentioned literature on structural change in the U.S. labor market suggests that earnings instability might have increased, at least for workers with medium or lower skills. Katz and Autor (1999), for example, in their review 
of the early literature on increasing earnings inequality, make the connection between rising earnings inequality and rising instability directly. Haider (2001) also explicitly draws a connection between growing earnings inequality and earnings instability. On the other hand, a prominent hypothesis in macroeconomics is that the 1980s ushered in a period known as the Great Moderation, reflected in declining levels of aggregate volatility (McConnell and PerezQuiros, 2000). While there is no necessary connection between aggregate volatility and volatility at the micro level (as noted by Davis and Kahn, 2008, and Dynan et al., 2012), some macroeconomists argue that a lack of decline in individual earnings volatility matching the aggregate volatility decline is intuitively difficult to explain (Sabelhaus and Song, 2010). Consequently, there is no consensus on whether labor market volatility should be expected to have risen, fallen, or remained stable.

The project which this Overview summarizes represents an effort to bring several important data sets to bear on the question of whether U.S. earnings volatility at the micro level has risen, fallen, or remained constant over the last several decades. It is motivated in large part by the disparate findings on this question which have appeared when different data sets have been used. The workhorse data set for estimating trends in individual earnings volatility in the U.S. has been the Panel Study of Income Dynamics (PSID), a longitudinal survey that has been ongoing since 1968 (and is hence the longest-running general-purpose socioeconomic panel in the world), which has attempted to maintain reasonable population representativeness and which asks extensive questions on labor market activity. The use of the PSID for the study of male earnings volatility began with Gottschalk and Moffitt (1994), who found male earnings volatility to have increased from 1970 to 1987 , with the largest increase occurring among the less educated. About a dozen PSID studies subsequent to the Gottschalk-Moffitt study have also 
found increases in male earnings volatility over time. ${ }^{1}$ However, no increase was found in at least one other panel survey, the Survey of Income and Program Participation (Celik et al., 2012) and, possibly more important, no increase and often a decline has been found in studies using administrative data from Social Security or Unemployment Insurance records (Sabelhaus and Song, 2010; Dahl et al., 2011; Celik et al.,2012; DeBacker et al., 2013; Guvenen et al., 2014; Bloom et al., 2017). The difference in trends found in administrative data, which are often presumed to be more accurate than survey data, suggests that there may be problems with the PSID survey data.

The project brings four different subprojects and six different data series to bear on this question, each using common samples, common definitions of volatility, and common other treatments of the data (trimming, treatment of nonworkers, imputations, and others). One paper reexamines the oft-used PSID, but adds to previous work by extending the time period up through 2016 (which turns out to be important) and by conducting a number of analyses of bias that might come from attrition and other threats to representativeness. A second paper uses data from the Current Population Survey, using earnings reports of individuals who are in the survey twice over a one-year period. But this paper also matches the CPS sample to Social Security earnings files, permitting a direct comparison of survey reports and administrative data reports for the same individuals. The third paper uses the Survey of Income and Program Participation (SIPP), a well-known Census Bureau survey intended to be representative of the population and which consists of a rolling series of 2-to-5-year panels, thereby permitting estimates of the volatility of year-to-year changes in earnings. But, like the second paper, this third paper also

\footnotetext{
1 See Dynarski and Gruber (1997), Haider (2001), Hyslop (2011), Keys (2008), Heathcote et al. (2010), Shin and Solon (2011), Dynan et al. (2012), Moffitt and Gottschalk (2012), Jensen and Shore (2015), and Carr and Wiemers (2018). A full listing of all studies, along with those using other data sets, can be found in Moffitt and Zhang (2018).
} 
employs a data set of Social Security earnings data matched to the SIPP survey respondents, again providing the opportunity to compare trends in earnings volatility between the two types of data. The fourth paper uses only administrative data, but data drawn from Unemployment Insurance (UI) wage records collected by employers and reported to state governments. The well-known file is called the Longitudinal Employer-Household Dynamics (LEHD) data set and has the virtual entire universe of earnings of UI-covered workers in the states that have provided their data. The importance of the LEHD is that not only does it have a vast sample size compared to the survey-based data sets, it has a different sampling frame-namely, the near-total universe of US workers and not just those who agreed to participate in a survey.

The four papers each focus on trends in male earnings volatility over the years for which they have data. The PSID goes back to 1970, the SIPP goes back to the early 1980s, the CPS goes back to 1995, and the LEHD goes back to 1998 . There is thus full overlap after 1998 and partial overlap in many earlier years. A short summary of the analyses and findings of each paper is given in this Overview. But the major findings of the four are, in brief, as follows.

First, the PSID analysis shows, contrary to statements often made in the literature, very little upward trend in earnings volatility after the 1980s. Changes in volatility after that time are dominated by cyclical movements which have been misinterpreted as trend growth. After the Great Recession, volatility in the PSID is headed down towards its level in the early 1990s.

Second, the analysis of the Social Security earnings data in the CPS shows no evidence of any trend after 1995, once imputed observations are omitted. CPS imputation rates are very high and have attracted a great deal of discussion in the literature, with many concerns for their accuracy (Andridge and Little, 2010). A key finding of the CPS analysis of the matched survey-administrative data is that, among non-imputed observations, volatility levels and trends 
calculated using the survey earnings reports are virtually identical to those calculated using the administrative data for the same individuals. Thus, there is no evidence of errors in survey reporting affecting conclusions about volatility in levels or trends. Further, inconsistency in trends in earnings volatility only appears when comparing those trends using the administrative earnings data to those using the earnings values imputed to individuals by the Census Bureau, which are quite different.

Third, the analysis of the SIPP survey and administrative data show some slight differences in volatility trends after the early 1980s. The administrative data show a slight upward trend and the survey data show a slight downward trend but the differences are small and both suggest a relatively flat trend in male earnings volatility. An investigation of the differences in earnings reports in the two types of data shows that much of the small difference in trends is a result of differences in the lower tail of the earnings distribution, which is much larger in the administrative data, which affects the average trend because the lower tail volatility is moving slightly differently than it is in the rest of the distribution.

Fourth, earnings volatility in UI records shows a relatively flat trend from 1998 to 2011 but with strong cyclical elements showing upward jumps in volatility in the early 2000s and during the Great Recession. Volatility after 2011 declines and ends up at a slightly lower level than it was in 1998. The decline after 2011 differs from that in the PSID and appears to be partly a result of differences in the size of the lower tail of the cross-sectional earnings distributions in the two data sets.

The conclusion drawn from the analyses is that, when common samples, methods, definitions, and treatment of the data are used, both survey and administrative data, both when matched and when not matched to each other, show essentially no significant long-term trend in 
male earnings volatility after about 1990. Increases in male earnings volatility are a thing of the past, but it also not declining, except possibly after the mid-2010s. This finding raises many questions for future research, which are discussed at the end of this Overview.

\section{Common Analysis Structure}

All four papers examine annual earnings of men 25-59 in each year of the data All analyses use simple and transparent summary measures of gross earnings volatility using the earnings change from one year to a subsequent year, either one or two years, depending on the data set. One measure uses the variance in the change in log earnings and a second uses what is called the arc percent change, which is simply the percent change in earnings relative to the average in the two years. The latter can be extended to the inclusion of men with zero earnings in one of the years. No attempt is made to decompose the variance of earnings changes into permanent and transitory components; this is left for future work. ${ }^{2}$ The baseline specification in all studies uses residuals from a regression of either the change in log earnings or the arc percent change on age and age squared, but sensitivity tests are conducted to that procedure by using earnings unadjusted for age. The baseline specification also trims the top and bottom one percent of the earnings distribution in each year; sensitivity tests to trimming are also discussed and, in fact, differences in the sizes of the tails of the earnings distribution in different data sets play a role in the analyses and explain some differences in volatility levels and trends. All papers first work with a sample of men who worked in both years before proceeding to an analysis of volatility when men with zero earnings in one year are included.

\footnotetext{
2 All decompositions into permanent and transitory components require identifying restrictions on what goes into each component and, indeed, the general linear ARMA model is not identified (Moffitt and Zhang, 2018, Online Appendix). However, as noted in the Conclusions, future work on trends in permanent and transitory variances would be of interest
} 
$\underline{\text { PSID }}$

The PSID paper (Moffitt and Zhang, 2020) covers the period 1970 to 2016. Earnings data in the PSID were collected on heads of household only and the analysis uses wage and salary income, excluding self-employment earnings. The trend in earnings volatility in the data is shown in Figure 1, along with the national unemployment rate. ${ }^{3}$ The figure shows that the trend in volatility follows a three-phase pattern, rising from the 1970s to the mid-1980s, exhibiting a stable trend around significant fluctuations from the mid-1980s to the mid-2000s, and rising thereafter. The dotted line in Figure 1 is a fit of the data to a $5^{\text {th }}$ order polynomial, which shows the three phases of the change more visibly. The figure also shows the unemployment rate, demonstrating that volatility exhibits strong countercyclicality, although, on average, volatility only falls in a recovery period after a lag. Moffitt and Zhang show that the increase in volatility in the first half of their observation period--from the early 1970s to the early 1990s--was much larger than in the second period--from the early 1990s to the final year, 2016. The percent increase in volatility was 150 percent in the former period and 20 percent in the latter. Important to this conclusion is the availability of several additional years of PSID data compared to past work, and those additional years show a continued decline in volatility after the Great Recession. In 2016, volatility had reached its mid-2000s level; if it were to decline only slightly more, it would reach its level in the early 1990s.

\footnotetext{
${ }^{3}$ All figures in this Overview will report the results using the arc percent change measure of volatility. The individual papers all report results using the change in log earnings, and find similar volatility trends but often differences in levels.
} 
In other results, the authors examined trends in the percentile points of the earnings change distribution, finding volatility over the periods when it was increasing to reflect a widening out at all percentile points but with the largest widening occurring at the top and bottom of the change distribution. Looking at trends in different parts of the cross-sectional distribution of earnings, the analysis reveals that the largest increases in the 1970s to the 1980s occurred at lower levels of earnings, consistent with Gottschalk and Moffitt (1994). An analysis which estimates volatility including movements into and out of employment shows that volatility is much higher in level when those movements are included in the volatility measure, but that the trends over calendar time are the same. This implies that movements into and out of employment are occurring in parallel with movements in positive earnings movements.

The authors conduct sensitivity tests to trimming by examining results using no trimming or greater than 1 percent trimming; the use of log earnings itself instead of regression residuals; adjusting for attrition in the PSID; gauging the effect of imputations for earnings values not reported by the respondent; and whether the exclusion of post-1968 immigrants could have affected the results. The authors conclude that none of these factors likely explain the measured trends in the data. However, they find that differences in the size of the left tail of earnings could have some impact on the differences in volatility trends in the PSID compared to administrative data sets, which typically have much larger left tails. In an analysis which compares trends in shares of part-year and full-year workers and their respective trends in volatility, the authors find that different trends in those shares in administrative data could produce smaller increases or even declines in volatility. Relatedly, the authors show that some of the papers using administrative data used real dollar trims at the bottom of the distribution rather than percentile 
point trends, and show that, in the PSID, real dollar trims often bias trends in volatility downward.

\section{$\underline{\text { CPS }}$}

The CPS paper uses matched one-year apart surveys with respondent-reported annual earnings linked to their Social Security earnings records (Ziliak et al., 2020). The analysis covers the years 1995-2015. The authors conduct most of their work on a sample of men for whom an earnings record could be found in the administrative data, necessarily therefore using a sample of men reporting positive earnings in both data sets. A major focus of the analysis is the treatment of earnings values which are imputed by the Census Bureau because respondents refused to answer or gave don't-know responses, or did not answer lead-in questions about whether they were employed. A very large average 45 percent of earnings observations in the CPS are imputed and that rate has been rising over time. The authors begin with a sample of those men with valid, non-imputed earnings and compare trends in one-year-apart earnings volatility calculated first from their survey-reported earnings and then from their administrativedata earnings. The results are shown in Figure 2, revealing two key findings. First, the two lines are almost identical, implying that survey reports of earnings changes are essentially identical in the two data sets. There is therefore no evidence of any biased survey reporting error in the CPS. Second, both series imply a virtual flat trend in volatility from 1995 to 2015, with modest countercyclical movements in the early 2000s and the Great Recession.

When the authors include earnings values that were imputed by the Census Bureau and compare volatility for that sample to its Social Security earnings data, the results show marked 
differences in both level and trend. In levels, volatility using the change in imputed earnings is much higher than that calculated from administrative earnings. This is a direct result of the fact that imputation in each year is done separately and without regard to earnings in the other year, and independent random imputation error in the two years will necessarily lead to a higher variance of earnings changes. ${ }^{4}$ In trend, while the administrative data show a flat trend in volatility very close to that found for the non-imputed administrative data, volatility calculated from imputed earnings shows a steady upward trend over time. This could arise from increasing rates of imputation, changes in the method of imputation, or both. ${ }^{5}$ The authors conclude that the imputation procedures used by the Census Bureau should lead analysts to avoid using the imputed earnings data in the CPS for the analysis of earnings dynamics.

In other results, the authors find that adjusting for attrition propensities (on observables) leads to higher levels of volatility but has no effect on trends. In addition, the analysis reports estimates on a subsample of household heads, for comparison with the PSID, finding both levels and trends in earnings volatility to be the same for heads and non-heads. An examination of volatility among different demographic groups finds declining earnings volatility among women and, while the less educated, racial minorities, and part-year workers have higher levels of volatility, they contribute little to volatility trends.

\footnotetext{
4 The level of earnings volatility for imputed observations is also higher than that for the non-imputed observations, although this is not necessarily a sign of bias if imputation is not independent of earnings levels and changes.

${ }^{5}$ Bollinger et al. (2019) show that most earnings nonresponse in the CPS comes in the tails of the distribution of true earnings and therefore is nonrandom.
} 
The SIPP is a rolling panel data set with new panels (or cohorts) introduced periodically, with 16 panels introduced over the period 1984 to 2008, and with each panel lasting from 2 to 5 years (Carr et al., 2020). The last year the authors have data for is 2012, so the data span the 1984-2012 period. The SIPP is intended to be representative of the U.S. noninstitutionalized population in the initial year of each panel. The individuals in 9 of the 16 panels have been linked to their Social Security earnings records, and the linking obtains all future and past earnings records for each matched individual, including periods before and after the survey panel in which they participated. The administrative data on the individuals in the panels run from 1980 to 2014.

The authors devote considerable attention to imputation in the survey data, for the SIPP, like the CPS, has high nonresponse rates to the earnings and employment questions — up to 50 percent imputed values for at least one component of earnings (earnings questions are asked for five separate components). Further, imputation rates have been rising over time. The imputation flags on the SIPP survey are complex and change over time, and the authors devote considerable effort to correctly identifying imputed values. They are able to construct a nonimputed annual earnings total for all individuals consistently defined over the period.

Figure 3 shows the estimated volatility trends for the survey and administrative data. In terms of levels, volatility is considerably higher in the administrative data than in the survey data, unlike the case for the CPS. But in terms of trends, the differences are small. There is a slight downward trend in the survey data if the first (1984) observation is compared to the last (2012) or if the average over the first half of the observation period is compared to the average over the second half. There is a slight upward trend in the administrative data if, again, the 
value in the first year (1980) is compared to the last (2014) or, again, if the average over the first half of the period is compared to the average over the second half. But the trends are very small for both data sets and the overall result is that both the survey and administrative data are very flat over the period, consistent with the CPS and the PSID.

The authors examine the importance of the left tail of the cross-sectional distribution of earnings in these results, finding that their administrative data have a much larger left tail than their survey data, a now-familiar finding. When they reweight the cross-sectional distributions of both the survey and administrative data to match those distributions to the PSID survey data— which are essentially missing the left tail—the level of volatility in the administrative data drops and is almost identical to that in the survey data, thereby almost completely explaining the differences in volatility levels initially found. This change reflects the also-common finding that volatility is higher at lower levels of earnings than at higher levels. As for trends, the reweighting has little effect on the volatility trend in the administrative data but has a small effect in flattening out the trend in the survey data, thereby narrowing the already small differences in trends found initially.

In other results, the authors conduct sensitivity tests to alternative measures of trimming, the use of earnings itself rather than earnings residuals, adjustments for attrition bias, and some limited tests for the effects of imputation on volatility trends. The results show little sensitivity to any of these factors. However, like the PSID analysis, the authors do find that trimming on real earnings levels instead of by percentile points, as some studies using administrative data have conducted, sometimes biases trends downward because an increasing share of the left tail (with high earnings volatility) is being trimmed out. 


\section{LEHD}

The LEHD analysis consist of administrative data only, drawn from UI earnings records, and covers the period 1998 to 2016 (McKinney and Abowd, 2020). Figure 4 shows estimated earnings volatility by year from the data. Volatility experiences countercyclical upward spikes in the early 2000s and from 2007-2011, consistent with the recessions in those years, but shows no net trend from 1998 to 2011. After 2011, it continues to fall and ends up somewhat below its initial level in 1998.

The flat trend from 1998 to 2011 is roughly consistent with the general stability of male earnings volatility found in the other data sets. The decline after 2011 is somewhat similar to the decline through 2016 found in the CPS, where volatility in the administrative data also declines to a level slightly lower than its pre-Recession value. But the SIPP administrative data as well as the PSID show a decline only back to pre-Recession levels, although the SIPP data only go through 2014 rather than 2016 and hence may decline further in the following two years.

In other analyses, the authors find that trimming and age-adjustment have no effect on their estimated trends in volatility. An analysis of separate trends in volatility of those with earnings increases and decreases shows that both have the same trend. The authors also study the separate trends for those who change jobs and those who do not, finding that earnings volatility has risen for the former and declined for the latter, although the share of job changers has also declined. Finally, the authors again examine the importance of the large left tail of the cross-sectional earnings distribution in the LEHD. They recalculate their trends in earnings volatility using the same minimum and maximum earnings used in the PSID paper described above (i.e., the 1 percent trim) and then also reweight the LEHD cross-sectional earnings data to match the distribution in the PSID, which is missing the large left tail in the LEHD. The resulting 
reweighted volatility series has a much lower level than the unweighted series, again reflecting higher volatility in the lower tail. Further, the trend over time after reweighting shows less of a decline after the Great Recession than does the unweighted LEHD, suggesting that the differences in volatility trends with the PSID in the post-Recession period could partly rise from differences in the representation of the left tail of earnings distribution. ${ }^{6}$

\section{$\underline{\text { Summary of Trends in All Six Data Series }}$}

Figure 6 shows the trends in all six data series on the same diagram. In terms of volatility levels, two of the administrative data sets (the LEHD and the SIPP administrative data) have the highest levels of volatility, although the CPS administrative data series is considerably lower and even below that of the PSID. As reported above, reweighting the LEHD and the SIPP administrative data to the PSID cross-sectional earnings distributions lowers the levels of their volatility down to the same ranges as represented by the SIPP survey data and the CPS data, thus making cross-sectional differences a major potential explanation for differences in volatility levels across data sets. However, in terms of trends, it is clear from Figure 5 that no data set shows any significant long-term volatility trend after the mid-1980s. The LEHD shows a slight decline but only after 2011, the PSID almost ends up where it was in the early 1990s, the two SIPP data series end up in their last year close to where they were in their first year, as do the two CPS data series. ${ }^{7}$

\footnotetext{
${ }^{6}$ As noted previously, both data sets find flat trends in volatility through 2011, but the PSID show a decline back to pre-Recession levels by 2016 while the LEHD shows a decline that falls below pre-Recession levels by that year. This suggests that volatility in the lower tail, which is missing from the PSID, may have fallen after 2011.

7 After all 6 data sets are reweighted to the cross-sectional distribution of the PSID, all 6 never fall outside of a narrow .07 to .18 range of the variance after 1990 . The LEHD has the smallest spread, ranging only over .12 to .14 range from 1998 to 2016.
} 


\section{Directions for Future Research}

The central finding of stability in earnings volatility among men in this project opens up a research agenda in a number of areas. One obvious one is extending the investigation into volatility among women and, more importantly, within the family. While the CPS paper in this project found declining volatility among women, consistent with some prior work (Keys, 2008; Hyslop, 2001; Dynan et al., 2012; Hryshko et al., 2018), an old literature in labor economics examines whether the family works as an insurance mechanism and whether spouses help smooth income and consumption at the family level (Holbrook and Stafford, 1971; Blundell et al., 2016). But if male volatility has remained constant and female earnings volatility has declined, what has happened to family income (and consumption) is unclear and depends on, among other things, husband-wife covariances. The analyses in this project have not particularly focused on family relationships or distinguished between married and unmarried men, which would have to be a first step in exploring these issues.

Several decompositions of earnings volatility would also be worth exploring given this project's findings. The standard decomposition into wage rates and hours or weeks worked is an obvious one (Abowd and Card, 1989), but more interesting is what the findings imply for job mobility. Earnings movements and job movements have long been understood to covary and there is a long literature on this topic (Topel and Ward, 1992; Diebold et al., 1997; Altonji et al., 2013). But whether the structure of that relationship has changed over time has not been sufficiently studied. Alone among the studies in this project, the LEHD analysis showed that 
the share of job changers among men has declined over time but their earnings volatility has increased. The former is consistent with other work in recent years suggesting that job mobility has declined in the US for reasons not fully understood (Hyatt and Spletzer, 2013; Davis and Haltiwanger, 2014; Molloy et al., 2016), But how that decline has netted out to stable earnings volatility would be of interest to know more about.

Permanent-transitory decompositions would be of major interest, although care needs to be made in making clear the identifying assumptions needed to distinguish them. Stability in earnings changes could arise from stability of both permanent and transitory components or from offsetting changes between them (including changes in their covariance). It matters both for understanding the labor market as well as for policy to know how they are changing, separately. In fact, as noted in the original paper in this literature, changes in cross-sectional earnings inequality can only arise if either permanent or transitory variances or both are changing over time (Gottschalk and Moffitt, 1994). How to reconcile the stability of overall earnings volatility found in these papers with changes in cross-sectional earnings inequality is related to permanent-transitory decompositions and therefore would also be of interest.

Finally, the papers have shown, once again, the importance of labor market heterogeneity by demonstrating how critical it is to examine earnings volatility in different parts of the earnings distribution, separating those in the lower tail from those in the rest of the distribution. It is known that the structure of the family and family insurance mechanisms, the structure of job mobility, and the relative importance of permanent and transitory components all differ for individuals at different earnings and skill levels. How and whether volatility and instability trends in all these dimensions have differed by those heterogeneity levels would appear to be a major dimension worthy of future exploration. 


\section{References}

Abowd, John M. and David Card. 1989. “On the Covariance of Earnings and Hours Changes.” Econometrica 57(2): 411-45.

Altonji, Joseph G.; Anthony A. Smith; and Ivan Vidangos. 2013. “Modeling Earnings Dynamics.” Econometrica 81(4): 1395-1454.

Andridge, Rebecca R. and Roderick J. A. Little. 2010. “A Review of Hot-Deck Imputation for Survey Non-Response.” International Statistical Review 78(1): 40-64.

Bloom, Nicholas; Faith Guvenen; Luigi Pistaferri; John Sabelhaus; Sergio Selgado; and Jae Song. 2017. "The Great Micro Moderation.” Working Paper.

Blundell, Richard; Luigi Pistaferri; and Itay Saporta-Eksten. 2016. “Consumption Inequality and Family Labor Supply.” American Economic Review 106(2): 387-435.

Bollinger, Christopher; Barry T. Hirsch; Charles M. Hokayem; and James P. Ziliak. 2019. "Trouble in the Tails? What We Know about Earnings Nonresponse Thirty Years after Lillard, Smith, and Welch.” Journal of Political Economy 127(5): 2143-85.

Carneiro, Pedro and Rita Ginja. 2016. "Partial Insurance and Investments in Children.” Economic Journal 126(October): F66-F95.

Carr, Michael D. and Emily E. Wiemers. 2018. New Evidence on Earnings Volatility in Survey and Administrative Data. American Economic Association Papers and Proceedings 108 (May): 287-91.

Carr. Michael D.; Robert A. Moffitt; and Emily E. Wiemers. 2020. "Reconciling Trends in Volatility: Evidence from the SIPP Survey and Administrative Data.” Working Paper. http://www.econ2.jhu.edu/people/moffitt/ES_MCRMEW_v9_2020-6-25.pdf (accessed $7 / 7 / 20)$

Carroll, Christopher D. 1997. "Buffer-Stock Saving and the Life Cycle/Permanent Income Hypothesis.” Quarterly Journal of Economics 112(1): 1-55.

Celik, Sule, Chinhui Juhn, Kristin McCue, and Jesse Thompson. 2012. Recent Trends in Earnings Volatility: Evidence from Survey and Administrative data. B.E. Journal of Economic Analysis and Policy 12 (2).

Dahl, Molly, Thomas DeLeire, and Jonathan A. Schwabish. 2011. Estimates of Year-to-Year Volatility in Earnings and in Household Incomes from Administrative, Survey, and Matched Data. Journal of Human Resources 46 (4): 750-74.

Davis, Steven J. and John Haltiwanger. 2014. “Labor Market Fluidity and Economic Performance.” Working Paper 20479. Cambridge: National Bureau of Economic Research. 
Davis, Steven J. and James A. Kahn. 2008. "Interpreting the Great Moderation: Changes in the Volatility of Economic Activity at the Macro and Micro Levels.” Journal of Economic Perspectives 22(4): 155-80.

DeBacker, Jason Matthew, Bradley T. Heim, Vasia Panousi, Shanthi Ramnath, and Ivan Vidangos. 2013. Rising Inequality: Transitory or Permanent? New Evidence from a U.S. Panel of Household Income 1987-2006. Brookings Papers on Economic Activity 2013 (4): 67-142.

Diebold, Francis X.; David Neumark; and Daniel Polsky. 1997. "Job Mobility in the United States.” Journal of Labor Economics 15(2): 206-233.

Dynan, Karen, Douglas Elmendorf, and Daniel Sichel. 2012. The Evolution of Household Income Volatility. The B.E. Journal of Economic Analysis \& Policy 12 (2): 1-42.

Dynarski, Susan and Jonathan Gruber. 1997. Can Families Smooth Variable Earnings? Brookings Papers on Economic Activity 1997 (1):229-303.

Friedman, Milton. 1957. The Permanent Income Hypothesis. In A Theory of the Consumption Function, 20-37. Elizabeth: Princeton University Press.

Gottschalk, Peter, and Robert Moffitt. 1994. The Growth of Earnings Instability in the U. S. Labor Market. Brookings Papers on Economic Activity 1994 (2): 217-72.

Gourinchas, Pierre-Olivier and Jonathan A. Parker. 2002. Consumption over the Life Cycle.” Econometrica 70(1): 47-89.

Guvenen, Fatih, Serdar Ozkan, and Jae Song. 2014. The Nature of Countercyclical Income Risk. Journal of Political Economy 122(3): 621-60.

Haider, Steven. 2001. "Earnings Instability and Earnings Inequality of Males in the United States, 1967-1991.” Journal of Labor Economics 19 (October): 799-836.

Hall, Robert E, and Frederic S Mishkin. 1982. The Sensitivity of Consumption to Transitory Income: Estimates from Panel Data on Households. Econometrica 50 (2): 461-81.

Heathcote, Jonathan; Kjetil Storesletten; and Giovanni L. Violante. 2010. "The Macroeconomic Implications of Rising Wage Inequality in the United States.” Journal of Political Economy 118 (August): 681-722.

Holbrook, Robert and Frank Stafford. 1971. "The Propensity to Consumer Separate Types of Income: A Generalized Permanent Income Hypothesis.” Econometrica 39(1): 1-21.

Hryshko, Dmytro, Chinhui Juhn, and Kristin McCue. 2017. Trends in earnings inequality and earnings instability among U.S. couples: How important is assortative matching? Labour Economics 48 (August). Elsevier B.V.:168-82. 
Hyatt, Henry R. and James R. Spletzer. 2013. “The Recent Decline in Employment Dynamics.” Journal of Labor Economics 2(3); 1-21.

Hyslop, Dean R. 2001. Rising U.S. Earnings Inequality and Family Labor Supply: The Covariance Structure of Intrafamily Earnings. American Economic Review 91 (4): 755-77

Jensen, Shane T, and Stephen H Shore. 2015. Changes in the Distribution of Earnings Volatility. Journal of Human Resources 50 (3): 811-36.

Katz, Lawrence F. and David H. Autor, 1999. “Changes in the Wage Structure and Earnings Inequality.” In Handbook of Labor Economics, Vol. 3A, eds. O. Ashenfelter and D. Card. Amsterdam and New York: Elsevier North-Holland.

Keys, B. 2008. Trends in Income and Consumption Volatility, 1970-2000. In Income Volatility and Food Assistance in the United States, ed. D. Jolliffe and J. Ziliak. Kalamazoo, Mich: W.E. Upjohn Institute.

Kim, Y-S.; T. Loup; J. Lupton; and F. Stafford. 2000. “Notes on the 'Income Plus’ Files: 19941997 Family Income and Component Files.” Institute for Social Research, University of Michigan.

Kim, Y-S. and F. Stafford. 2000. "The Quality of PSID Income Data in the 1990s and Beyond.” Ann Arbor: Institute for Social Research, University of Michigan.

Levhari, David and Yoram Weiss. 1974. "The Effect of Risk on the Investment in Human Capital.” American Economic Review 64(6): 950-963.

McConnell, Margaret M. and Gabriel Perez-Quiros. 2000. “Output Fluctuations in the United States: What Has Changed since the Early 1980s?” American Economic Review 90(5): 1464-76.

McKinney, Kevin L. and John M. Abowd. 2020. "Male Earnings Volatility in LEHD Before, During, and After the Great Recession.” Working Paper. http://arxiv.org/abs/2008.00253 (accessed 8/4/20).

Moffitt, Robert A. and Peter Gottschalk. 2012. Trends in the Transitory Variance of Male Earnings: Methods and Evidence. Journal of Human Resources 47(1): 204-36.

Moffitt, Robert A. and Sisi Zhang. 2018. "Income Volatility and the PSID: Past Research and New Results.” American Economic Association Papers and Proceedings 108 (May): 27780 .

Moffitt, Robert A. and Sisi Zhang. 2020. "Estimating Trends in Male Earnings Volatility Using the Panel Study of Income Dynamics.” Working Paper. http://www.econ2.jhu.edu/people/Moffitt/moffitt-zhangdraft2020-7-7\%20final.pdf (accessed 7/7/20). 
Molloy, Raven; Christopher Smith; Riccardo Trezzi; and Abigail Wozniak. 2016. "Understanding Declining Fluidity in the U.S. Labor Market." Brookings Papers on Economic Activity (1): 183-237.

Sabelhaus, John, and Jae Song. 2010. The Great Moderation in Micro Labor Earnings. Journal of Monetary Economics 57 (4): 391-403.

Shin, Donggyun, and Gary Solon. 2011. Trends in Men’s Earnings Volatility: What Does the Panel Study of Income Dynamics Show? Journal of Public Economics 95 (7-8). Elsevier B.V.:973-82.

Taubman, Paul and Michael Wachter. 1986. “Segmented Labor Markets.” In Handbook of Labor Economics, Vol.2, eds. Orley Ashenfelter and Richard Layard. New York and Amsterdam: Elsevier North-Holland.

Topel, Robert H. and Michael P. Ward. 1992. "Job Mobility and the Careers of Young Men.” Journal of Political Economy 107(2): 439-479.

Ziliak, James P.; Charles Hokayem; and Christopher R. Bollinger. 2020. “Trends in Earnings Volatility using Linked Administrative and Survey Data.” Working Paper. http://ukcpr.org/sites/ukcpr/files/research-pdfs/DP2020-01.pdf (accessed 7/7/20). 
Figure 1: PSID Volatility, 1972-2016

0.30

12

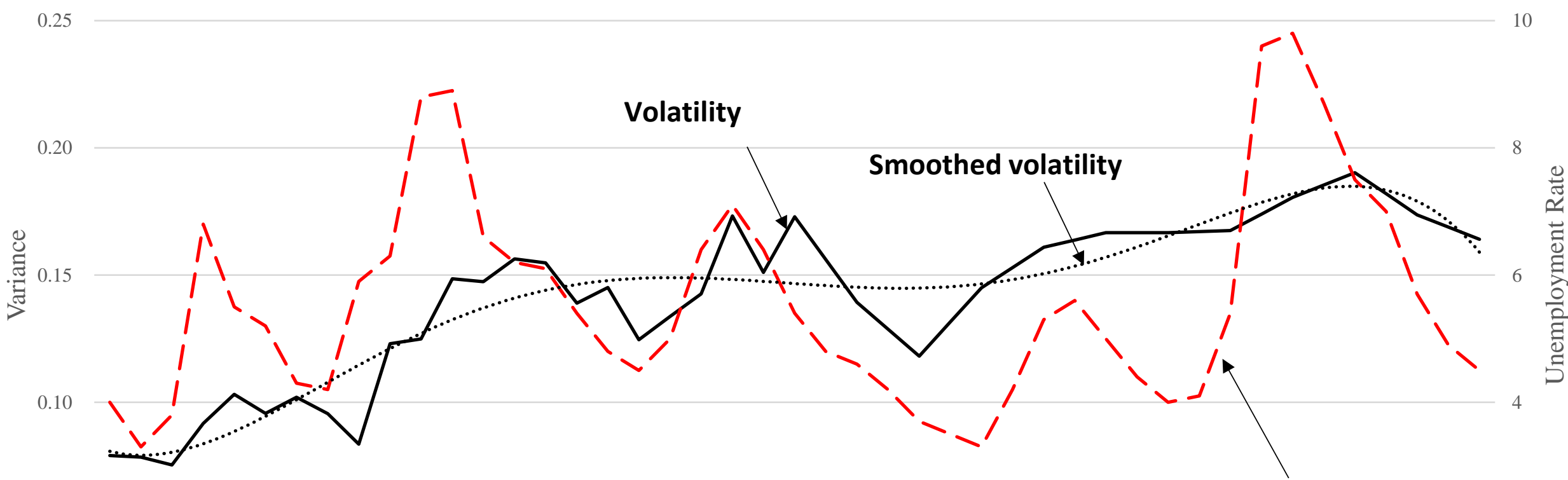

0.05

Unemployment rate

2

0.00

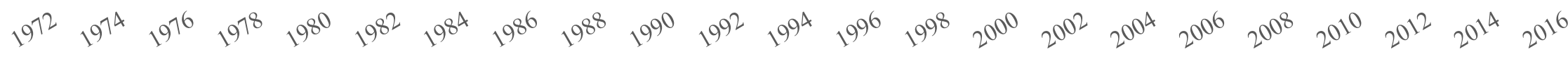

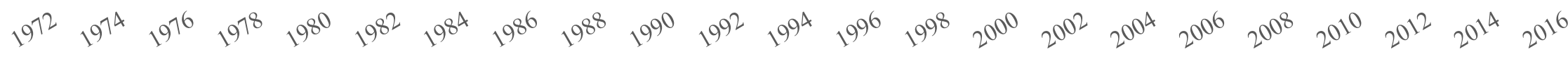

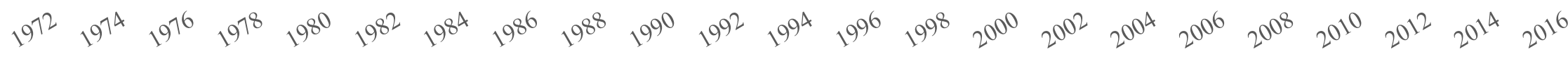

0 
Figure 2: CPS Volatility, 1995-2015

0.30

0.25

0.20

\section{Administrative}

0.15

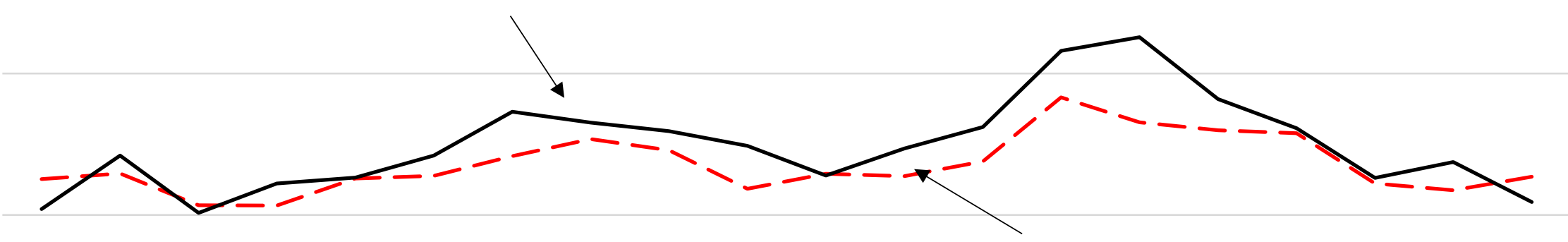

\section{Survey}

0.05

0.00

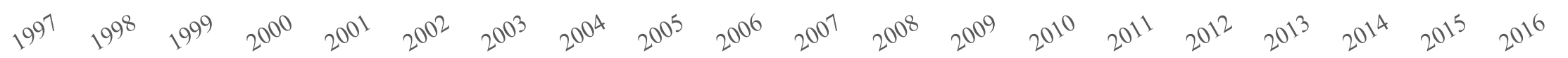




\section{Figure 3: SIPP Volatility: 1908-2014}

0.3

\section{Administrative}

0.25

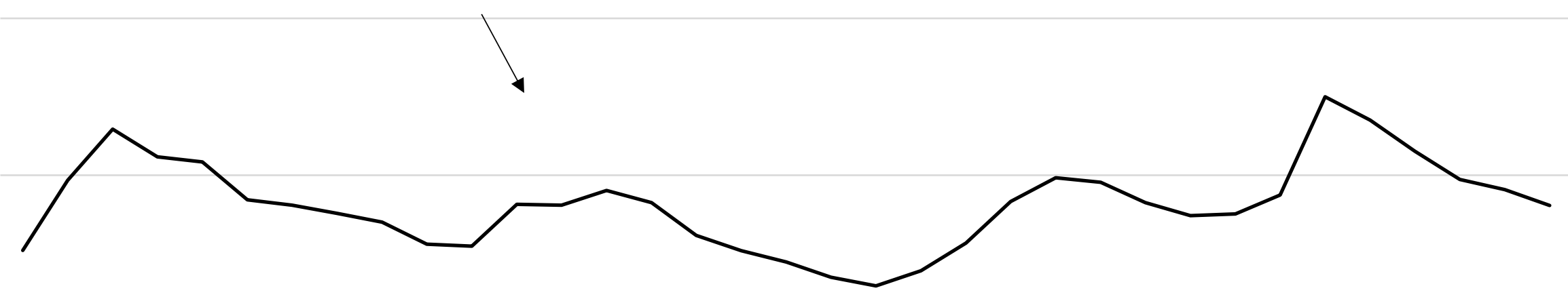

0.15

0.1

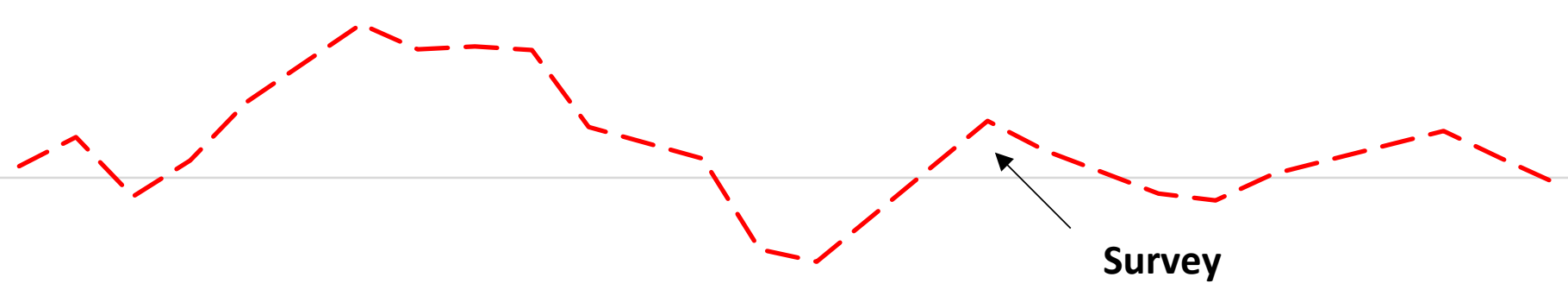

0.05 
Figure 4: LEHD Volatility, 1998-2016

0.3

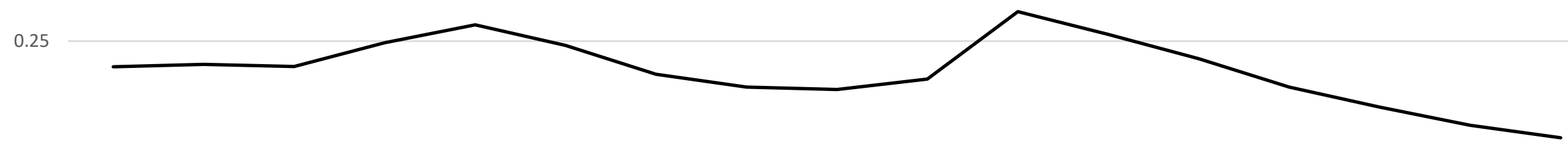

0.2

0.15

0.1

0.05

0

1998

1999

2000

2001

2002

$200^{3} \quad 2004$

2005

2006

2007

$200^{8}$

2009

2010

2011

2012

2013

$202^{4}$ 


\section{Figure 5: Volatility of PSID, CPS, SIPP and LEHD}

0.30

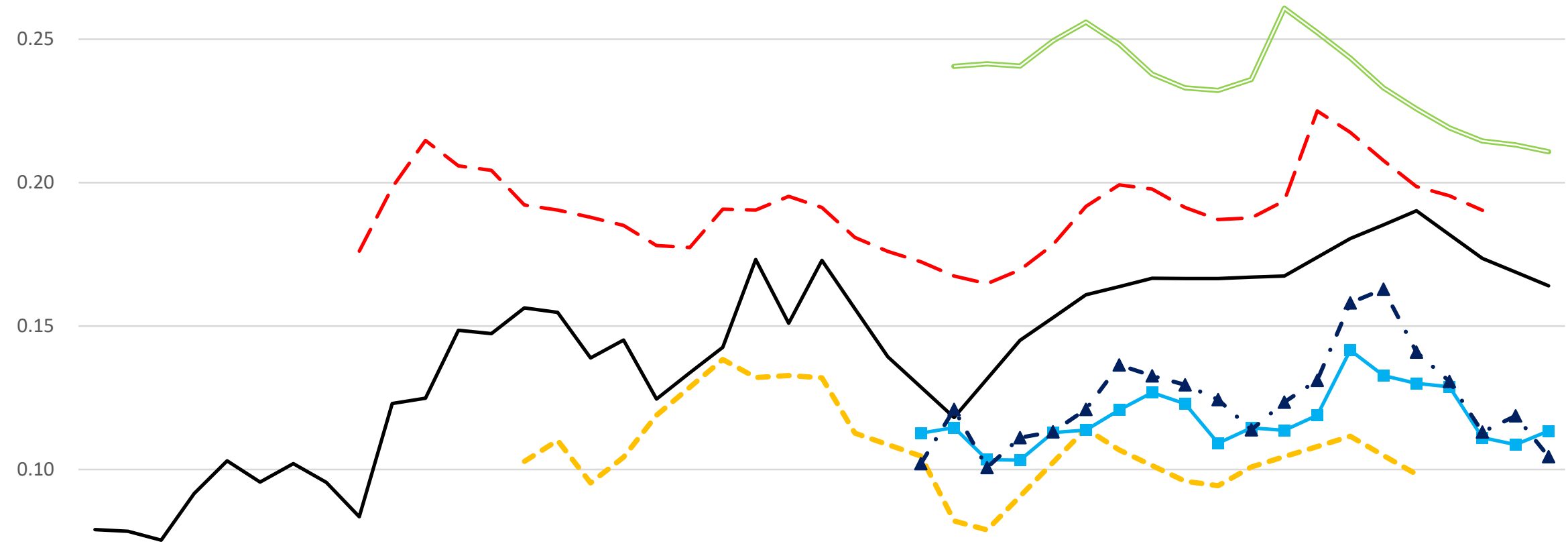

0.05

0.00

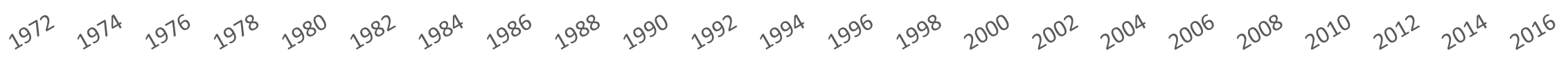

$\longrightarrow$ PSID - - SIPP-Administrative $-\infty$ SIPP-Survey $\longrightarrow$ LEHD CPS-Survey $-\Delta-$ CPS-Administrative 